\title{
OUDERDOMSBEPALING BIJ HERTEN VAN HET GENUS RUSA \\ (VOORLOPIGE MEDEDELING)
}

DOOR

\author{
A. C. V. VAN BEMMEL N.PH. DOCTS \\ Zoölogisch Museum, Buitenzorg
}

\section{INLEIDING}

Wanneer men bij een systematisch onderzoek van herten tracht om de soortsen raskenmerken vast te stellen, stuit men op moeilijkheden van velerlei aard. Om te beginnen zijn herten sexueel dimorph en vertonen zij bovendien een duidelijke periodiciteit, die samenhangt met de sexuele cyclus. De laatste uit z:ch onder meer in het periodiek afwerpen en regenereren van het gewei, klieractiviteit e.d. Daarnaast komt, merkwaardig genoeg ook bij tropische soorten, een seizoensvariatie voor, die zich vooral uit in kleur en toestand van het haarkleed.' De sexueel-cyclische variatie en de seizoensvariatie gaan bij de soorten in gematigde streken hand in hand, omdat daar de sexuele cyclus aan. het seizoen gebonden is. Bij tropische soorten is dit in veel mindere mate het geval. Daar volgt ieder individu zijn eigen cyclus en het verloop hiervan kan, zelfs bij individuen van één populatie, aanmerkelijke schommelingen vertonen.

Voor de systematicus doen zich nog andere storende factoren voor. Er vertonen zich n.l. verschillen tussen voor het wild gunstige en ongunstige jaren, die zich in geweiontwikkeling en beharing kunnen uiten. Döderlein gaf hiervan een bekende beschrijving (Abh. Bay. Ak. Wiss. 31, 3, 1927). Tenslotte heeft men nog te maken met ouderdomskenmerken, die de meeste moeite veroorzaken en de grootste foutenbron zijn omdat ze het minst voor de hand liggen.

Reeds meerdere malen is er op gewezen, dat, ook nadat de dieren de geslachtsrijpheid bereikt hebben, nog belangrijke wijzigingen optreden in lichaamsbouw, gewei van de mannelijke dieren, beharing en in de verhouding van de schedelmaten. Op de eerste drie punten wordt in de Europese jachtliteratuur uitgebreid ingegaan. Aan de wijzigingen, die in de onderlinge verhouding van de schedelmaten optreden, hebben A. RörIG (Anat. Anzeiger Jena 26, 1905, pp. I7-25) en O. Ingebrigtsen (Bergens Mus. Aarbok, H, 2, 7, 
I922-23 pp. I-262 \& Nyt. Mag. Naturvid., Bd. 65, I927 1)) belangrijke studies gewijd.

Samenvattend komen wij dus tot de conclusie, dat, bij een systematisch onderzoek in deze groep, de factoren: sexe, cyclisch stadium, seizoen (c.q. jaar) en ouderdom moeten worden uitgeschakeld en dus alleen dieren van dezelfde sexe, hetzelfde cyclisch stadium en dezelfide leeftijd vergeleken mogen worden, terwijl met seizoens-(c.q. jaarfactoren) rekening moet worden gehouden. De meeste van deze factoren zijn zonder veel moeite af te leiden, doch voor de bepaling van de ouderdom is het allereerst nodig om over betrouwbare criteria te beschikken, waaraan de leeftijd van het museum-materiaal kan worden vastgesteld.

Men zal deze kenmerken bij voorkeur aan de schedel trachten te vinden. De gebr. Nehring (Forstwiss. Centr. Bl. 33, I889, pp. 23 I-243 \& „Wild und Hund" 1904, pp. 679-682, 697-699, 712-715) hebben aan het gebit van Europese herten ( $C$. elaphus $\mathrm{L}$.) uitgebreide ouderdomsbepalingen uitgevoerd ${ }^{2}$ ). Voor de Oost-Aziatische vertegenwoordigers van het genus Rusa ${ }^{3}$ ) is, voor zover mij bekend, nog niets op dit gebied gepubliceerd.

In deze leemte te voorzien is de bedoeling van deze voorlopige mededeling.

\section{METHODE}

Aan de hand van de resultaten van NeHring's onderzoek trachtte ik de fraaie serie „Javaanse herten" (-Rusa timorensis cum subspec.) in de collectie van het Zoölogisch Museum Buitenzorg volgens dezelfide methode op ouderdom te rangschikken. Dit bleek doenlijk, omdat bij een zo extreem variabele groep als de Cervidae de morphologische bouw van het gebit juist uiterst constant is en bijgevolg interspecifieke en zelfs intergenerieke vergelijking mogelijk moet zijn. Op deze wijze kon ik een serie opstellen, die in grote lijnen met die van NeHRING overeen kwam. Als belangrijke aanwijzing gebruikte ik Nehring's kenmerk van de afslijting der incisiviforme tanden, waarmee een grof criterium voor: zeer oud, oud, minder oud, jong, werd verkregen. Ik nam verder voorlopig aan, dat een Rusa, die op hetzelfde stadium staat als een overeenkomstig exemplaar van $C$. elaphus, ook inderdaad even oud is. Iets wat à priori betwijfeld zou kunnen worden, omdat veelal wordt aangenomen, dat tropische soorten sneller verouderen dan overeenkomstige vormen uit gematigde streken. Om het zeer speculatieve geheel te voltooien moet ik er nog op wijzen, dat NeHRiNG's ouderdomsbepaling op vrij veel critiek stuitte, omdat men zijn theorie van de gelijkmatige afslijting van het gebit onbewezen en de maximale ouderdom van 20 jaar voor $C$. elaphus te laag achtte. Tot zover

I) $\mathrm{Mij}$ momenteel alleen als exerpt toegankelijk.

2) De moderne Duitse jachtliteratuur is mij niet toegankelijk.

3) Systematische en nomenclatorische beschouwingen blijven hier geheel buiten bespreking. Hierop hoop ik t.z.t. nader in te gaan. 
waren mijn resultaten dus nog geheel hypothetisch. Het ging er nu om, be wijzen te vinden.

Het Zoölogisch Museum te Buitenzorg beschikt over een collectie afworpgeweien en onderkaken van $\sigma^{\gamma}$ herten, afkomstig van het Yang-plateau, geschonken door de heer A. LEDEBoER, die volgens ouderdom gerangschikt heetten te zijn. Of de heer LEDEBOER deze rangschikking zelf heeft uitgevoerd, dan wel in samenwerking met de heer P. F. FRANCK, destijds taxidermist bij het Zoölogisch Museum, is mij niet bekend. Evenmin weet ik, of de leeftijdstaxaties op veldwaarneming berusten, waartoe de heer LEDEBOER in zijn uitstekend beheerd revier zeker de gelegenheid bezat, dan wel op post-mortem taxatie. De etikettering is door FrANCK geschied. De rangschikking is zeker aan critiek onderhevig. De onderkaaksgebitten dragen een leeftijdstaxatie, die veel lager ligt dan die waartoe de methode-NenRing zou leiden en de volgorde is ongetwijfeld voor wijziging vatbaar. Een schedel in onze collectie, eveneens van Ledeboer afkomstig, met het bijschrift in Franck's handschrift: „Etwa 8-jähriger Feisthirsch” is bovendien veel ouder, niet alleen volgens de methode-Nehring, maar ook volgens de serie van Ledeboer \& Franck zelf. Volgens Nehring zou deze bok 14 jaar, volgens Ledeboer \& FRANCK Io jaar moeten zijn. Er rees dus bij mij gerechtvaardigde twijfel aan de bruikbaarheid van deze gegevens, nog versterkt door de wel zeer geidealiseerde voorstelling, die van de gewei-ontwikkeling wordt gegeven. Zonder afbreuk te doen aan de vakkennis van Ledeboer \& FRANCK, acht ik daarom hun serie wetenschappelijk nog te weinig exact om als uitgangspunt te dienen. $\mathrm{Bij}$ het nagaan van het beschikbare materiaal trof $\mathrm{ik}$, nadat de bepaling volgens Nehring reeds was uitgevoend, nog een kleine collectie schedels aan, afkomstig van dieren uit gevangenschap, die ik aanvankelijk als onbruikbaar voor systematisch onderzoek had uitgeschakeld. Hieronder bevonden zich enkele schedels van dieren, die als jong kalfje op een onderneming waren gekomen, daar in ongeveer normale omstandigheden en met een grote mate van vrijheid waren opgegroeid en waarvan de juiste leeftijd bekend was. Bij het invoegen van deze schedels in de volgens NeHRING opgestelde serie verkreeg ik dus een controle op de gevolgde methode en deze bevestigde de theoretische leeftijd, voor zover het materiaal betrof van niet ouder dan 5 jaar. Jammer genoeg was het oudere materiaal uit gevangenschap niet voldoende van betrouwbare aantekeningen voorzien, dan wel abnormaal ontwikkeld of pathologisch misvormd. Ook het materiaal van Rusa equina cum subspec. uit gevangenschap voldeed niet aan de eisen. De leeftijdsbepaling hiervan moest dus geheel door vergelijking met de serie Rusa timorensis worden uitgevoerd. Exact genoeg zijn de gegevens omtrent de tandwisseling, waarvoor voldoende materiaal van Java en één specimen van Soemba met bekende leeftijd beschikbaar was. Voor de dieren boven 5 jaar geef ik de bepaling voor wat ze is : een met grote kans op waarschijnlijkheid uitgevoerde schatting.

Zoals Nehring reeds aangaf, vertoont het gebit van de bovenkaak betere 
aanknopingspunten dan dat van de onderkaak. Hij nanı speciaal de $M^{\mathbf{1}}$ als criterium aan, en dit blijkt voordelen te hebben. De afslijting van het gebit is n.l. ook onderhevig aan individuele verschillen. Bij eenzelfde afslijting van de $M^{1}$ zijn bij het ene individu' de daarachter gelegen gebitselementen, bij een ander individu de daarvoor gelegen gebitselementen iets verder afgeslepen. Een correlatie tussen de afslijting van het gebit en de herkomst, i.c. het milieu, kon ik niet aantonen, evenmin als een onderscheid tussen de afslijting bij dieren van verschillende sexe.

\section{RESULTATEN}

Gebrek aan plaatsruimte verhindert inij voldoende afbeeldingen op te nemen om alle gevonden ouderdomskenmerken te demonstreren. Ik wil mij hier

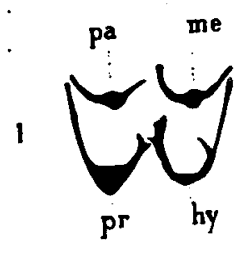

2

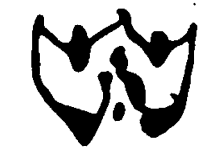

3

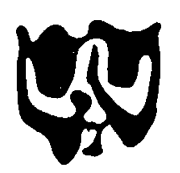

4

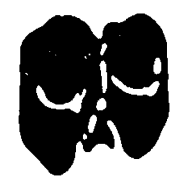

5

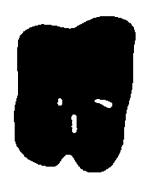

6

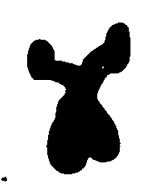

Fig. I-6. Schema van de wijziging in het dentine-patroon van de linker $M 1$ bij Rusa timorensis Blainv. I: 3 jaar; 2: 5 jaar; $3: 9$ jaar ; $4: 12$ jaar; $5:$ I5 jaar; $6: 20$ jaar

daarom bepalen tot het geven van één practisch bruikbaar kenmerk, n.l. het verloop van het dentinepatroon op de kroon van de $M^{1}$

3 jaar (fig. r). Het dentinepatroon bestaat uit vier halve manen, tie tussen de emaillijsten te voorschijn komen, onderling geheel door emaillijsten zijn gescheiden en in het centrum iets zijn verbreed. De gevorkte caudale einden van de linguale halve manen zijn duidelijk.

5 jaar (fig. 2). De halve manen verplaatsen zich, wat de pa. en de me. betreft, iets buccaal, wat de pr. en hy. betreft iets linguaal. In het centrum van de halve manen verbreedt zich de dentine de kaakas. Het cingulum- 
element is nu ook aangeslepen en het dentine wordt zichtbaar. Het dentine van pa. en me. komt in onderling contact, het dentine van pr. verbindt zich oraal met dat van pa., het dentine van hy. verbindt zich caudaal

SCHEMA VAN DE TANDWISSELING BIJ HET GENUS RUSA

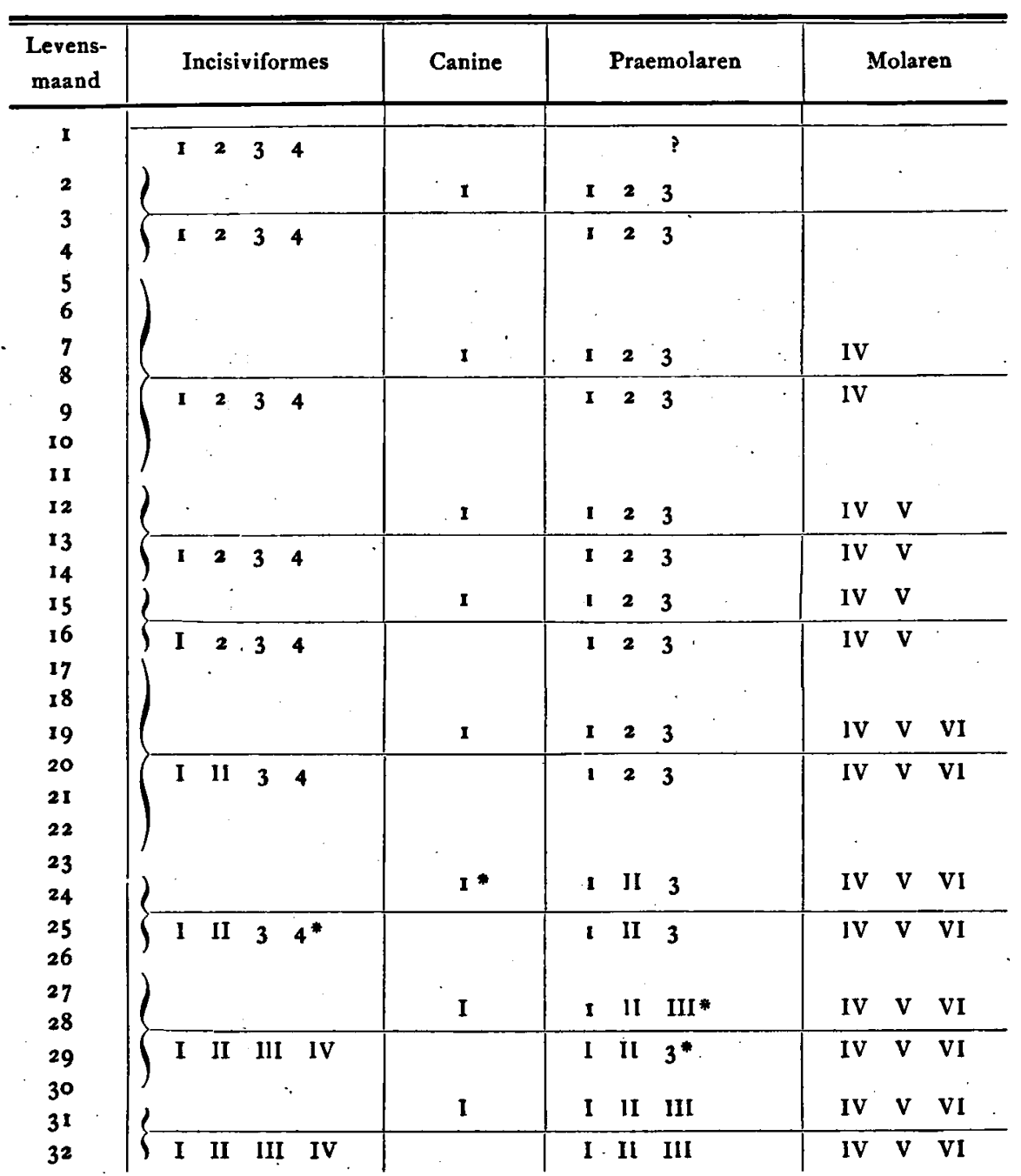

Deciduate elementen Arabische cijfers.

Blijvende elementen Romeinse cijfers.

* Onderhevig aan individuele variatie.

met dat van me.; het dentine van pr. en hy. is nog gescheiden. De gevorkte einden van pr. en hy. zijn reeds zeer onduidelijk geworden.

\pm 9 jaar (fig. 3). Er treedt contact op tussen het dentine van pr. en hy. via het cingulum-element; direct contact is nog niet aanwezig, doch beiden 
zijn slechts door een zeer fijn emaillijstje gescheiden. De bifurcatie $\checkmark$ van pr. en hy. is verdwenen.

\pm 12 jaar (fig. 4). Alle vijf dentine-eilanden zijn nu versmolten. De scheiding wordt nog slechts door enige rudimentaire emaillijsten aangeduid.

\pm 15 jaar (fig. 5). Totale versmelting is opgetreden; de emaillijsten zijn geheel of bijna geheel verdwenen. Het cingulum is totaal verdwenen. De kies is kleiner geworden en heeft zich in de richting van kaakas versmald.

\pm 20 jaar (fig. 6). Tot op de wortel afgesleten. Centraal staan de wortels nog meestal met elkaar in verbinding.

Melkgebit (tabel). Wat het melkgebit betreft, dit leverde de minste moeilijkheden op. Ik geef hier een schema in de geest van de door NiTsche (Forst- und Jagdkalender, Judeich; ex Raesfeld: „Das Rotwild”, $3 \mathrm{e}$ dr., I920, Berlin, p. 22) voor C. elaphus ontworpen tabel. Daarbij vallen enkele typische verschillen op. Bij het onderzochte $R u s a$-materiaal komen de permanente incisiven en caninen later, de permanente praemolaren iets eerder door dan bij $C$. elaphus. Vooral merkwaardig is het zeer vroegtijdig optreden van de derde molaar. Ik heb de indruk - maar het materiaal is niet voldoende voor een exacte conclusie - dat bij Rusa equina c. subspec. de derde molaar iets later optreedt dan bij Rusa timorensis cum subspec. Het doorbreken van de permanente canine in de bovenkaak kan individueel nogal uiteenlopen, evenals de volgorde van het doorbreken bij de permanente praemolaren. De formules in de bijgaande tabel geven het gemiddelde weer van het onderzochte juveniele materiaal (34 ex. $R$. timorensis cum subspec., I I $R$. equina cum subspec.) Van de deciduate praemolaren blijft er in enkele gevallen een tot in het derde jaar functionneren. Dit kan de $\mathrm{Pd}_{1}$, maar ook de $\mathrm{Pd}_{3}$ zijn, zowel in de boven- als in de onderkaak of in een van beiden. 